\title{
Identifying qualities of physics graduate students valued by faculty
}

\author{
Lindsay Owens, ${ }^{1}$ Benjamin M. Zwickl, ${ }^{2}$ Scott V. Franklin, ${ }^{2}$ and Casey W. Miller ${ }^{1}$ \\ ${ }^{1}$ School of Chemistry and Material Science, Rochester Institute of Technology, 84 Lomb Memorial Drive, Rochester, NY 14623 \\ ${ }^{2}$ School of Physics and Astronomy, Rochester Institute of Technology, 84 Lomb Memorial Drive, Rochester, NY 14623 \\ (Dated: October 1, 2019)
}

Faculty members involved in graduate admissions decisions have to determine who will be offered admissions to their respective graduate programs. In this study, we interviewed faculty at four institutions who currently serve or have served on their program's graduate admissions committee. The focus of this study was twofold: first, to explore what qualities faculty value in graduate students and second, to identify what sources of evidence faculty utilize in determining if a student possesses a desired quality. Results from these interviews showed that while qualities such as content knowledge and programming skills were valued, non-cognitive qualities such as self-motivation, resilience, and self-learning were also highly desired. The faculty noted that while current admissions practices can easily identify if a student has taken certain coursework, they typically lack the means to quickly assess non-cognitive qualities, which must often be inferred from the contents of personal statements and letters of recommendation. These results suggest that transparency on the part of graduate programs to better advertise the qualities they desire will assist letter writers and students writing personal statements to increase the impact of their application materials.

2019 PERC Proceedings edited by Cao, Wolf, and Bennett; Peer-reviewed, doi.org/10.1119/perc.2019.pr.Owens Published by the American Association of Physics Teachers under a Creative Commons Attribution 4.0 license. Further distribution must maintain attribution to the article's authors, cover page, and DOI. 


\section{INTRODUCTION}

A typical application for a prospective physics graduate student includes a transcript (detailing institution, coursework, and GPA), standardized test scores (General GRE and Physics GRE), letters of recommendation, a personal statement, and a CV (highlighting leadership roles, presentations, and publications). Faculty serving on their department's graduate admissions committee determine who will be offered admission to their program based upon a culmination of the application materials. Prior research has shown that faculty place substantial value in quantitative measures such as an applicant's GPA and Physics GRE scores [1]; this is problematic because Physics GRE scores have been shown to be bias against women and underrepresented minorities [2, 3]. While Potvin does suggest that letters of recommendation and personal statements play a key role in the analysis of an application [1], these documents have also been shown to be potentially biased [4]. For example, in letters of recommendation the language used to describe men can be "outstanding and excellent," while women are described as "hardworking and caring" [4]. Understanding how physics and astronomy faculty conceptualize their "ideal" graduate student allows us to identify what qualities they value and would be seeking in those letters of recommendation and personal statements. This information allows letter writers and By ensuring that faculty's most desired qualities are highlighted for each applicant, we have the potential to level the playing field for all applicants.

In this paper, we will discuss views of seventeen faculty members from four different institutions on their "ideal" graduate student. Analysis of interviews will be presented showing two broad themes: (1) research-field specific skills, which varied depending on the nature of the faculty's research (theoretical, computational, experimental, or observational); and (2) independence, a non-cognitive quality that emerged from descriptions of self-motivation and resilience. Independence was desired by the majority of faculty, regardless of research field. Implications for graduate admissions practices in light of this work will also be discussed.

\section{METHODS}

During an in-person visit to each institution, faculty participated in individual semi-structured interviews. All interviews were audio-recorded and transcribed. Participants in this research consisted of 17 faculty members (13 male, 4 female) from four separate graduate programs, as described in Table I. All faculty participants were serving or had served on the graduate admissions committee for their program. This collective group of faculty was diverse in term of the research interests and fields (experimental, theoretical, observational, and computational).

The interview protocol used in this research invited faculty to share their opinion on a variety of topics related to gradu-
TABLE I. Faculty Participants.

\begin{tabular}{cccc}
\hline \hline Program & Type & Women & Men \\
\hline Physics \& Astronomy & Private Not for Profit & 2 & 4 \\
Astrophysics & Private Not for Profit & 1 & 4 \\
Physics & Private Land-Grant & 1 & 1 \\
Physics & Public & 0 & 4 \\
\hline \hline
\end{tabular}

ate admissions. Specific to this study, faculty were asked to describe their "ideal" graduate student. Then, faculty were asked how they selected for the qualities they had identified. The goals of the first question were to provide an open space for faculty to identify many characteristics of someone that would likely be successful in graduate school, and to identify how faculty ranked non-cognitive qualities (e.g., persistence, self-motivation) relative to traditional academic achievements. The goal of the second question was to identify if, where, and how non-cognitive qualities were being used by faculty during the admissions process.

Transcripts were coded in NVivo to identify desired qualities and what pieces of a graduate application typically contain evidence of those qualities. A list consisting of emergent qualities was developed by the first author. The list of qualities itself and a large sample of coded text from multiple interviews were discussed and modified by the first and second authors to ensure agreement of qualities identified. For example, one faculty member said that his ideal graduate student would "persist when things inevitably go wrong." Similarly, another faculty member said that they would want a student who "doesn't get frustrated at the first roadblock." Both quotes describe a similar quality and were labeled as resilient by the authors, even though the word resilience was not explicitly used in either description. Discussions between the first two authors also resulted in the collapsing of multiple identified qualities into a singular overarching theme.

\section{RESULTS}

Several qualities were repeatedly mentioned across faculty interviews as characteristics of an "ideal" physics graduate student, the most frequently cited being: self-motivation; self-learning; resilience; and programming skills (see Table. II). Faculty added that these qualities were necessary for any physics graduate student's success. The first four of these qualities described a student's non-cognitive abilities, rather than academic measures. This section will discuss themes in two contexts: qualities mentioned in research-field specific contexts, and those that span across faculty specializations. Many faculty stated that they considered an entire application when making admissions decisions, but claimed that noncognitive qualities of students within a personal statement and 
letters of recommendation played a key role.

\section{A. Theme: Research-Field Specific Qualities}

There were several cases where the sought qualities of an "ideal" graduate student were driven by a faculty member's research. For example, an astrophysics professor indicated that any prospective student needed to have robust knowledge of thermodynamics and quantum mechanics in order to be able to comprehend the latest literature in the field. Faculty doing theoretical research tended to call out having a "strong mathematical background" or a "broad range of math courses," in addition (but not always) to quantum mechanics. Many of the faculty whose research was theoretical or computational in nature cited a need for programming skills, including a specific need for graduate students to know Python in order to understand and generate code to run simulations or evaluate complex mathematical models.

"I think the ideal [graduate student] would be somebody with a strong background in physics and theoretical and computational [research] because we do theoretical and computational work. And without any knowledge of programming, nothing much can be achieved."

For faculty running experimental research laboratories, qualities such as creativity and tinkering were frequently mentioned. These faculty indicated a need for students to be able to play around with experimental setups, find creative ways to solve problems in the lab, and identify workarounds during equipment failures.

Faculty looked at transcripts to assess content knowledge, including determining if applicants had taken key courses (such as thermodynamics or quantum mechanics for the astrophysics professor mentioned above).

Applicants have two common ways to indicate their programming skills. First, they could specifically call out programming skills within CV or their personal statements in relation to their research or a class project. Second, some programs specifically asked students to rank their expertise with MATLAB or Python.

\section{B. Theme: Independence}

All but one interviewee cited one or more non-cognitive qualities in their description of an "ideal" graduate student, many of which tie into an underlying theme of independence. Non-cognitive qualities often held more weight than research-specific qualities. Three quotes from various faculty members highlight the importance of non-cognitive qualities:

"Mainly for me, is the motivation, I mean, from them. I don't care too much about the background. It's the motivation and the resilience that essentially-so if they want to do something because they are really interested in doing it, and if they have the ability to adapt, or to change things, and things like that, that's all I need. The rest, they learn."
"So the minimum requirements are ability to get things done, some sort of drive, and capacity, and desire to accomplish things. That is above all the most important thing."

"Enthusiastic, self-motivated, those are two big ones."

Three frequently cited non-cognitive qualities were selfmotivation, resilience, and self-learning. Self-motivation and self-learning were the two most commonly used phrases and descriptions within the interviews. These three qualities together suggested that the faculty participants ultimately desired a graduate student who was independent in nature.

One faculty member indicated that both self-motivation and resilience were critical for success in graduate school, and synthesized how resilience stemmed out of selfmotivation. He indicated that students who lacked intrinsic drive also likely lacked resilience. "People who are successful in graduate school and in life are the people who, even when the job is hard, and demanding, and unpleasant, still want to come in, and do the work as well as they possibly can, and get to the answer. And many students have not developed that or at least have not formalized their thinking about it yet. Say, 'Why did you come to grad school?' and they say, 'I don't know.' You say, 'Okay. Well, I don't know is not going to get you through your fourth year when it seems like this thing is never going to end, and it's misery.",

Self-motivation also emerged in the faculty's discussion of undergraduate research experiences. Simply having the experience was insufficient; faculty were more interested in if the student demonstrated initiative in their undergraduate research, whether it be seeking out the opportunity (such as applying for an REU) or taking ownership of a project.

Resilience was mentioned as critical for success by faculty whose research was predominately experimental or computational in nature. One faculty member wanted a graduate student who "can go and just isn't bothered by challenging issues or doesn't get sort of frustrated at sort of the first roadblock that pops up." The use of resilience was pushed further by indicating that students not only needed to bounce back in the face of unexpected delays but that they needed to be able to do it quickly. "You need to be able to keep pressing forward consistently without, kind of, losing great amounts of time to random things that come along the way."

Graduate students able to identify gaps in their knowledgebase and proceeded to independently fill those gaps were highly desired. According to the faculty, someone who could teach themselves new skills or content had the ability to continually make progress on their research without the assistance of faculty, post-docs, or more senior graduate students, who were often pressed for time on their own projects.

"The ability to work out their problems a little bit for themselves before they come talk to me, right? They can dig in a little bit. Being able to think about what the next steps in a problem have to be, again, so they don't have to always be asking me about that. [...] I can't necessarily have all the time I would love to be able to devote to the student to say, 'Okay. Let's work on something together' so they could do that, right? I mean, so kind of by necessity, I kind of need stu- 
TABLE II. Desired Qualities in Graduate Students. T = Theoretical, E = Experimental; $\mathrm{C}=$ Computational; $\mathrm{O}=\mathrm{Observational}$.

\begin{tabular}{|c|c|c|c|}
\hline Code & Definition & Sources of Evidence & Research Type \\
\hline $\begin{array}{l}\text { Content } \\
\text { Knowledge }\end{array}$ & $\begin{array}{l}\text { Background knowledge in physics, astro- } \\
\text { physics, or mathematics }\end{array}$ & Transcripts & $\mathrm{T}, \mathrm{E}, \mathrm{C}, \mathrm{O}$ \\
\hline $\begin{array}{l}\text { Programming } \\
\text { Skills }\end{array}$ & Experience with specific languages & $\begin{array}{l}\text { Transcripts; CV; } \\
\text { Applications }\end{array}$ & $\mathrm{T}, \mathrm{C}$ \\
\hline Self-Learning & $\begin{array}{l}\text { Identifying gaps in one's own knowledge } \\
\text { and independently filling those gaps }\end{array}$ & $\begin{array}{l}\text { Recommendation Let- } \\
\text { ters, Personal Statements }\end{array}$ & $\mathrm{T}, \mathrm{E}, \mathrm{O}$ \\
\hline Resilient & $\begin{array}{l}\text { Continues to progress even when encoun- } \\
\text { tering roadblocks; ability to quickly re- } \\
\text { cover from difficult/frustrating situations }\end{array}$ & $\begin{array}{l}\text { Recommendation Let- } \\
\text { ters, Personal Statements }\end{array}$ & $\mathrm{E}, \mathrm{C}$ \\
\hline $\begin{array}{l}\text { Self- } \\
\text { Motivated }\end{array}$ & $\begin{array}{l}\text { Independently drive research projects; } \\
\text { takes initiative; achievement orientation }\end{array}$ & $\begin{array}{l}\text { Recommendation Let- } \\
\text { ters, Personal Statements }\end{array}$ & $\mathrm{T}, \mathrm{E}, \mathrm{C}, \mathrm{O}$ \\
\hline
\end{tabular}

dents that are willing to just be like, 'Okay. I'm going to go work on something for a week, and I'll make progress. And I don't always have to just be asking a question every day.",

Every faculty member cited a student's personal statement or letters of recommendation as the medium used to identify these non-cognitive qualities. Identifying what counts as evidence of these qualities was less clear cut, with the faculty often citing having to infer this from those sources. For example, "you can look in the letters of recommendation people write for comments that speak to whether someone's really the type who is going to always show up and keep at something or not." Others were able to give examples of situations that would show evidence of certain qualities. For example, a student can highlight how they took ownership of a project in a personal statement to serve as evidence of being an independent researcher.

"The students can sort of describe what they did in the projects. I like to see them be able to do that. Because sometimes they can't, and then it's suddenly clear that okay, that faculty member, whoever, drew up the research project and the student was only tangentially somehow associated with it."

\section{DISCUSSION AND CONCLUSION}

The goal of this study was to understand what physics and astronomy faculty consider to be the "ideal" graduate student. There were two broad themes that emerged from the data. The first was research-field specific qualities, which by their nature varied between research disciplines. The other theme described a non-cognitive quality at the core of many faculty descriptions: independence.

\section{A. Theme: Research-Field Specific Qualities}

Every interviewed faculty member from the four universities that were sampled had an active research program. While some faculty focused more on the needed content or skills specific to their research than others, this was not linked to a given research field nor to a specific department.

In general, the faculty desired a student who had the content background most appropriate for someone in their research field. Quantum theorists desired a strong background in mathematics and quantum mechanics. Astrophysicists cited astronomy, thermodynamics, and quantum mechanics content as key, depending on their specific projects. Only two faculty volunteered an explanation for why understanding such content was important: it allowed students to hit the ground running and not have to wait until after they completed all their graduate coursework to begin research. When probed, most faculty claimed very generally that understanding specific content was necessary for research.

The ability to hit the ground running also served as an explanation for why programming skills were so heavily desired. While many faculty noted that programming could be learned, they rationalized their preference for students already having this skill by saying that they would not have as much of a learning curve when taking on a new project.

\section{B. Theme: Independence}

Faculty cited many different qualities of their "ideal" graduate student that centered around a common theme of being an independent researcher. For example, faculty indicated that graduate students who were intrinsically driven were also more likely to take initiative to solve problems or even drive future research agendas on their own. For faculty who already considered themselves to be pressed for time, the idea of having a graduate student that did not need frequent meetings in order to progress forward with research was highly desired.

The theme of independence was also seen when faculty explained why having an undergraduate research experience was so important for graduate school. Faculty were the most interested in students being able to describe contributing unique ideas to projects, initiating their own research project, 
or taking a current project in a new direction.

Finally, content knowledge (research-field specific) and self-learning (non-cognitive) shared an interesting link. One faculty member described how having prerequisite knowledge meant that graduate students could be more self-learning in terms of being able to read and understand literature relevant to their research field. In fact, one of the computational faculty discussed their own current undergraduate student as exhibiting all the traits of the perfect graduate student. In citing the student's extensive content knowledge and her ability to self-teach any new information, the professor said that these two traits make the student more independent, and therefore "low stress and low maintenance,", which were seen as critical because of the extensive amount of time and stress involved in teaching, mentoring students (undergraduate and graduate), and maintaining an active research agenda.

\section{Limitations and Implications}

This study has three notable limitations. First, faculty that were recruited all had experience with their program's admissions process, and self-selected into the study. Therefore, the opinions of other faculty at these same institutions were not captured. Second, none of the participants identified as any racial minority, an issue that could be addressed in future research. Third, all four programs that participated in this study were $\mathrm{PhD}$-granting research-intensive universities and therefore did not capture the thoughts and opinions of faculty at the master's granting level, who may desire different qualities in masters-level physics graduate students.

There are two notable implications of this study. First, knowing what faculty on admissions committees are searching for to determine if a student possesses the qualities they desire gives insight to those writing letters of recommendation for students. Specifically highlighting a student's ability to take initiative, independently progress on a project, or teaching themselves new content or skills will contribute to the positive impact that a letter of recommendation can have. In addition, students applying to physics and astronomy graduate programs should describe goals that they have set and achieved, personal contributions to research projects, and any problems that they have had to overcome. Second, since there was some variance on exactly what qualities faculty were looking for in applicants, we suggest that admissions committees provide directions or guiding points to let students know the content sought from their personal statements, thus allowing applicants to know what to showcase in their application.

This work was supported by NSF NRT-1633275.
[1] G. Potvin, D. Chari, and T. Hodapp, Investing approaches to diversity in a national survey of physics doctoral degree programs: The graduate admissions landscape, Physical Review Physics Education Research 13, (2017).

[2] C. Miller, B. Zwickl, J. Posselt, R. Silvestrini, and T. Hodapp, Typical physics Ph.D. admissions criteria limit access to under- represented groups but fail to predict doctoral completion, $\mathrm{Sci}$ ence Advances, 51 (2019). doi:10.1126/sciadv.aat7550

[3] C. Miller, and K. Stassun, A test that fails, Nature, 510, pp. 303304 (2014). doi:10.1038/nj7504-303a

[4] J. Posselt, Inside Graduate Admissions. Cambridge MA: Harvard University Press (2016). 